\section{The synthesis of length within and between perceptual systems*}

\author{
EUGENE ABRAVANEL \\ The George Washington University, Washington, D.C. 20006
}

Two experiments are reported comparing the accuracy of Ss in making length combinations visually, haptically, and intersensorally. It was hypothesized that there would not be significant differences among the three conditions for perceptual combinations of length, because length is a highly familiar dimension that is capable of being cognitively organized. The hypothesis was supported, and the findings were related to other research comparing intra- and intersensory processes.

In this paper we are reporting a study comparing intra- and intersensory integration where the major concern is with the process of actually combining or joining a pair of percepts to construct a larger product, i.e., the sum of their independent parts. The synthesis of parts to form larger wholes is, in one respect, a fundamental perceptual achievement of the most general kind (Koffka, 1935). But, where the parts are widely separated or in linear configurations, the organization may be considered a higher-level perceptual and cognitive achievement. It may be likened to the organization referred to by Birch and Lefford (1967) as "perceptual synthesis." Yet, with the exception of a few studies comparing performance among the blind and the sighted while making haptic form combinations (Worchel, 1952; Juurmaa, 1969), there is little known about the normal ability to make haptic combinations as compared with visual combinations. Likewise, we have little information regarding configural or additive integrations across perceptual systems.

Findings from several studics (Abravanel, 1971; Caviness, 1964; Cashdan, 1968; Rudel \& Teuber, 1964) indicate that intramodal visual equivalence matches are superior to either intrasensory haptic or intersensory matches. The findings are for adults matching shape properties. Conversely, a number of researchers (Kelvin, 1954; Kelvin \& Mulik, 1958) suggest that visual and haptic systems operate equivalently, and that intersensory matching is basically no different from intrasensory matching. In the case of length estimation, Teghtsoonian and Teghtsoonian (1965) found that

\footnotetext{
*This research was supported by Biomedical Sciences Support Grant FR-07019-03 from the General Research Supporl Branch, Division of Research Resources, Burean of Health Professions Education and Manpower Training, National Institutes of Health.
}

perceived visual and haptic lengths were both linear functions of physical length, with very similar exponents.

The question posed here is how well Ss synthesize lengths visually, haptically, and between these two perceptual systems. Research to date suggests two reasonable but contradictory outcomes. One hypothesis would predict greatest accuracy for intramodal visual combinations, while considering both intramodal haptic combinations and intermodal combinations as essentially similar. A second hypothesis, the one herein accepted, is that no significant differences among conditions, visual, haptic, or intermodal, would result in the estimation of length combinations. Reasonably short lengths (no more than the combined span of the two hands) are readily perceivable haptically and visually. Moreover, the adult perceiving length is likely to unitize a length and associatively compose its parts in a way that relies more heavily on cognitive schemes than on peculiarities specific to each perceptual system (cf. Gibson, 1966, for a similar view). Therefore, visual, haptic, or haptic-visual combinations would be referred to a common schematization and would be expected to be roughly equivalent in accuracy.

\section{EXPERIMENT 1}

Subjects

The Ss were 90 voluntecr undergraduate students at The George Washington University, with $30 \mathrm{Ss}$ participating in each condition. Approximately equal numbers of males and females were included in each condition.

\section{Materials and Apparatus}

The stimulus materials consisted of a series of wooden bars, $2 \times 2 \mathrm{~cm}$ in width and $6,7.5,9$, and $13 \mathrm{~cm}$ in length. The bars were all painted a homogeneous green color.

The device used for the visual equivalence adjustment measured $42 \times 10 \mathrm{~cm}$ and contained a variable white tape (a metal circular ruler) which was fastened behind an opening $(1 \times 33 \mathrm{~cm})$ in the Masonite front of the device. The $S$ instructed the $E$ in adjusting the length of line to match his perception.

In order to separate vision from haptics, an occlusion box measuring $50 \times 30 \mathrm{~cm}$ was used. The $S$ was able to place his hands beneath the screening curtain in the front end of the box and haptically explore for length with vision occluded.

\section{Procedure}

The Ss were assigned randomly to one of three conditions of length combination. Under each condition, 10 estimates were made by adjusting the variable-length device to match the perceived estimate of combined lengths.

The length pairings under all conditions were as follows: $6+6 \mathrm{~cm}, 7.5+7.5 \mathrm{~cm}, 9$ $+9 \mathrm{~cm}, 13+13 \mathrm{~cm}, 15+15 \mathrm{~cm}, 9+6 \mathrm{~cm}$, $6+13 \mathrm{~cm}, 7.5+13 \mathrm{~cm}, 15+9 \mathrm{~cm}, 15+$ $7.5 \mathrm{~cm}$. The order of paired combinations was randomized across Ss. The three conditions were as follows:

Condition 1: Visual-visual combination. Two bars were placed at eye level, with the long side of each slightly oblique to the S's line of regard and at a separation of $3 \mathrm{ft}$ so that the $S$ could not see both objects at once in his visual field.

Condition 2: Haptic-visual combination. One bar was placed at eye level, with the long side slightly oblique to the S's line of regard (as in Condition 1) at a distance of $11 / 2 \mathrm{ft}$ from the $S$. The other bar was placed behind the occlusion screen for the $S$ to perceive haptically with both hands.

Condition 3: Haptic-haptic combination. The two bars were placed behind the occlusion screen obliquely to the $S$ and at different elevations (3-in. difference) in order to prevent him from directly joining the two lengths. Otherwise, the $S$ was free to perceive the lengths haptically as he chose.

\section{Results}

A comparison of error levels for the three conditions was not significant $(F=1.24, d f=2 / 87, p>.10)$. See Table 1 . The effect of line lengths was significant $(F=17.71, \quad d f=9 / 80, \quad p<.01)$, with absolute levels of error greater for the longer length combinations.

\section{EXPERIMENT 2}

This experiment was designed to study the same intra- and intersensory length combinations as in Experiment 1, but with drawing as the metlod of reproduction. The method of reproduction by means of drawing is different from reproduction by means of adjustment in two essential ways. First, drawing requires a greater emphasis 
Table 1

Means and SDs of Errors for Three Conditions of Length Combinations in Experiments 1 and 2

\begin{tabular}{llccc}
\hline & \multicolumn{2}{c}{$\begin{array}{c}\text { Experiment 1 } \\
\text { (Adjustment) }\end{array}$} & SD & \multicolumn{2}{c}{$\begin{array}{c}\text { Experiment 2 } \\
\text { (Drawing) }\end{array}$} \\
\cline { 2 - 5 } & $\overline{\mathrm{X}}$ & $\overline{\mathrm{X}}$ & $\mathrm{SD}$ \\
\hline Visual-Visual & $\mathbf{2 . 0 9}$ & $\mathbf{1 . 7 3}$ & $\mathbf{2 . 6 4}$ & 2.66 \\
Haptic-Haptic & $\mathbf{2 . 0 3}$ & $\mathbf{1 . 5 3}$ & $\mathbf{3 . 2 8}$ & 2.54 \\
Haptic-Visual & 1.97 & $\mathbf{1 . 7 6}$ & $\mathbf{3 . 0 2}$ & $\mathbf{2 . 9 5}$ \\
\hline
\end{tabular}

Note $-N=90$ for each experiment, with 30 Ss per condition.

on memory for the perceived combined lengths because the $S$ forms his impression of the combination and then must turn away from it in order to make an equivalent line drawing. Second, the act of drawing is representational and in some sense more "active-manipulatory" than instructing the $E$ to adjust a variable line to match a perceptual combination.

Ninety $S s$ participated in this experiment, with 30 Ss in each of the three conditions. The apparatus and the stimulus materials were the same as those in Experiment 1, but in place of the variable length adjustment device, the $S$ was provided with a sheet of white paper $(22 \times 45 \mathrm{~cm})$ with a line ruled from end to end. With a black marker pen, he drew a line indicating his perception of the combined lengths of the two wooden bars. A new sheet was provided for each trial.

\section{Results}

Table 1 presents the results for the three conditions of length estimation. Analysis of variance for the main effect of conditions was not significant $(F=1.14$, df $=2 / 87, p>.10$ ). Again, there was a significant effect of line length $(F=15.10$, $\mathrm{df}=9 / 80, \mathrm{p}<.01)$, with absolute levels of error greater for the longer length judgments.

For each condition, reproduction by adjustment gave lower mean error levels than did reproduction by means of drawing. The differences were significant for the haptic-haptic combinations $(\mathrm{t}=7.31, \quad$ df $=58, \quad \mathrm{p}<.001), \quad$ the haptic-visual combinations $(\mathrm{t}=5.27$, $\mathrm{df}=58, \mathrm{p}<.001)$, and for the visual-visual combinations $(t=2.98, \mathrm{df}=58, \mathrm{p}<.01)$.

\section{DISCUSSION}

The activity of perceptually and cognitively synthesizing two lengths within and between perceptual systems has been found to be comparable, supporting the hypothesis of no major differences for integrations where the dimension is well-practiced and appropriate for vision or haptics (as length is). Perceptual combinations of the kind performed by our Ss appear to require an active effort of synthesis, and active-combinatorial imagery seems to be at work. However, the key to comparability of accuracy across conditions may lie in the cognitive operations of unitizing and composing lengths, which occur in similar fashion visually and haptically, or when a length is perceived by each system. As such, the process may be considered to be "supramodal" (cf. Gibson, 1966, for a related notion). It is probably this factor which chiefly accounts for the similarity among conditions here, by comparison with other research that reports differences in accuracy, depending upon the perceptual systems involved and whether performance is intra-or intersensory.

The greater accuracy for adjustment than for drawing as a method of reproduction probably resulted from the increased memory requirement imposed by the drawing procedure, and suggests that active, self-directed methods of reproduction are not always the most accurate.

Björkman (1967) has suggested that we rephrase the typical question and that instead of asking whether intrasensory or intersensory matching is more accurate, it is more fruitful to ask whether intra- and intersensory variances are the same or different. In his study, Björkman (1967) had Ss match sandpapers of different grit within and across perceptual systems. The variances of matched stimuli were found to be approximately three times as large when matching was performed intersensorally as compared to intrasensorally. This result may hold true for surface textures, but it was not the case in the present investigation, where Ss were dealing with a familiar dimension, such as length. It would seem, therefore, that research comparing intra- with intersensory perception must take account of the dimension selected for study and the extent to which it enables the $S$ to utilize cognitive operations or strategies that are largely independent of any specific perceptual system.

\section{REFERENCES}

ABRAVANEL, E. Active detection of solid shape information by touch and vision. Perception \& Psychophysics, 1971, 9, 000-000.

BIRCH, H. G., \& LEFFORD, A. Visual differentiation, intersensory integration, and voluntary motor control. Monographs of the Society for Research in Child Development, 1967, 32, Whole No, 110 .

BJÖRKMAN, M. Relations between intramodal and crossmodal matching. Scandinavian Journal of Psychology, 1967, 8, 65-76.

CASHDAN, S. Visual and haptic form discrimination under conditions of successive stimulation. Journal of Experimental Psychology, 1968, 76, 215-218.

CAVINESS, J. A. Visual and tactual perception of solid shape. Unpublished doctoral dissertation, Cornell University, 1964.

GIBSON, J. J. The senses considered as perceptual systems. New York: Hough ton-Mifflin, 1966.

JUURMAA, J. Optification tendency in tactual spatial manipulation. Reports from the Institute of Occupational Health, Helsinki, 1965 , No. 68.

KELVIN, R. P. Discrimination of size by sight and touch. Quarterly Journal of Experimental Psychology, 1954, 6, 23-24

KELVIN, R. P., \& MULIK, A. Discrimination of length of sight and touch. Quarterly Journal of Experimental Psychology, 1958, 10, 187-192.

KOFFKA, K. Principles of Gestalt psychology. New York: Harcourt-Brace, 1935.

RUDEL, R. G., \& TEUBER, H.-L. Crossmodal transfer of shape discrimination by children. Neuropsychologia, 1964, 2, 1-8.

TEGHTSOONIAN, M.. \& TEGHTSOONIAN, R. Seen and felt length. Psychonomic Science, $1965,3,465-466$.

WORCHEL, P. Space perception and orientation in the blind. Psychological Monographs, 1951, 65 , No, 15.

(Accepted for publication August 13, 1970.) 